result followed paracentesis now, I should hold the operator, and not the operation, to blame.

4. The deliberate opening of the side for a simple serous effusion has, I believe, been rarely practised, and rightly, for do what we will it is practically impossible, I believe, to prevent the effusion becoming purulent. That certainly happened at any rate in this case, in spite of the strictest antiseptic precautions. In this case, with so strong a tuberculous history in the family and with the strong presumption that the disease was of tuberculous nature, it seemed especially desirable to do nothing which might lead to an empyema. So I resisted the pressure put upon me to open the side as long as I could, and it was only after putting the whole case before the family and insisting that they should share in the responsibility of the decision that $I$ at last consented. My fears were fully confirmed, for although I did not confess it I felt many times tempted to despair of her recovery and to reproach myself for having yielded to the pressure put upon me. So far as the operation was concerned it was a complete success. The anxiety was caused, not by the condition of the pleura, but by the general condition of the patient, and this still remains a puzzle to me, for I cannot see any plausible explanation of the fever and rapid failure of health. There was not enough discharge to account for it, and there never was any retention of pus. Still there is the fact that she nearly died, and at times I felt almost without hope of getting her through. No signs of tubercle ever developed, and except for the effects of her pleurisy the patient seemed sound.

5 . Not the least remarkable part of the case is the complete restitutio ad integrum. There is now but very little external deformity, the lung has expanded, healthy breathing is andible everywhere, and I believe that when the tube is at last out there will be little but the scar to show what has been the matter. Yet the lung was completely compressed for about eighteen months, and another eighteen months were spent in getting well.

\section{THE OBSTETRICAL SOCIETY OF LONDON AND THE MIDWIVES QUESTION.}

Being an Abstract of the Inaugural Address delivered before the Society on March 6th, 1895.

BY F. H. CHAMPNEYS, M.D., F.R.C.P.,

President of the Society; Lecturer on Midwifery, and Physician and Accoucheur to St. Bartholomew's Hospital.

Dr. Champneys began by admitting that the Society's year opened with a disagreeable situation. He said "The General Medicai Council has threatened us with anathema for infringing the Medical Act and deceiving the public; it has even hinted at the word " infamous" being applied to us (in a strictly professional sense, of course), and all the consequences which follow the application (in a strictly professional sense) of that adjective. We have been guilty of examining midwives, of giving them certificates (or diplomas), of saying that we had done so, and of expressing our opinion that those who passed were " skilled midwives, competent to attend natural labour." This we have done for twenty-three years without let or hindrance; and as some men have suddenly waked up and found themselves famous, we have suddenly waked up and found ourselves (nearly, but not quite, and in a strictly professional sense) "infamous."

Now this requires a little explanation. Those of you who read the medical journals have noticed that for some little time agitators have been going about the country endeavouring to stir up an opposition to midwives, and particularly (please observe) to "skilled" midwives-that is, women who have received some sort of regular training, and have been taught how not to infect their patients, and when to call in the doctor.

Their interest in the Obstetrical Society is touching, but it is to be observed that their real object is not to " mend" but to "end" our examinations. Among the phrases which" have served these agitators may be noticed one that we are "creating a new order of medical practitioners."

This is as correct as the classical definition of the crab. which was criticised by Cuvier; it is perfectly accurate, except that (1) we have not "created" any persons at all; (2) midwives are not "medical practitioners" (in the technical sense); and (3) if either doctors or midwives are "new" I fear that history tells us with no uncertain voice that midwives antedated doctors by an enormous length of time. It is hardly too much to say that midwives must have begun nine months after there were two women and one man on the earth."

Dr. Champneys then briefly sketches the history of midwives in England. The Church, Chamberlen, and Harvey all advocated the instruction and licensing of midwives. He notes that Her present Majesty is the first queen ever attended in her confinement by a man. He recapitulates the proposals and Bills projected since 1813 for the examination and registration of midwives. These efforts at legislation are doubtless well known to readers who take an interest in the question. The Report of the Select Committee of the House of Commons on Midwives' Registration (August 8th, 1893) is quoted at length. In this report the rights of the practitioner were especially considered; in fact, it concludes thus :

"Your Committee desire to refer to the apprehension expressed by certain witnesses belonging to the medical profession. lest their interests might be injuriously affected by an improvement in the status of the midwives. The great preponderance, however, of medical and other evidence, having regard to both the authority and number of the witnesses, was to a contrary effect. Your Committee, therefore, whilst giving due consideration to the expression of such fears, believe that the suggested injury is not likely to prove serious, and they are of opinion that medical men will not only be relieved of much irksome and ill-paid work, but also that improved knowledge on the part of midwives will induce them to avail themselves more frequently, and at an earlier stage than at present, of skilled medical assistance in time of emergency and danger. On this point your Committee had full and substantial evidence."

Dr. Champneys dwells on the charge of the Recorder to the grand jury at the Old Bailey on January 8th, 1894, where great regret was expressed that the registration of midwives was not compulsory. "Anyone at present," said the Recorder, " could call herself a midwife, however ignorant she might be of the very first principles of her duties." All great nations excepting the United States and the British Empire have regulations for the control of midwives.

He next dealt with the history of the Obstetrical Society in relation to this question. "On November 4th, 1870" (said Dr. Champneys) " the Council passed a resolution in favour of the institution of a voluntary examination for midwives. ${ }^{1}$ This resulted from a committee under the presidency of Dr. Hall Davis. At the annual meeting of the Society, January 3rd, 1872, the scheme of such an examination, with by-laws, was presented to the Society and passed unanimously. It is essentially the same as at present, and the law referring to the granting of the certificates runs thus: " $V$. That, on satisfying the Board of Examiners as to her qualifications, the midwife should receive a diploma certifying that she is a skilled midwife, competent to attend natural labours.'2

At the annual meeting, January 6th, 1875, the President (Dr. Tilt) in his address said : 'Last year Lord Aberdare and Mr. Stansfeld were in office; they favourably entertained the views repeatedly brought forward by the Society, and they were prepared to bring in a Bill for the better education and registration of midwives, when a change of Ministry convinced your Council that the question must be left in abeyance. Ours is the only civilised country that has left unregulated the midwifery of the humbler classes, and it is a disgrace to obstetric medicine that there should be no means of preventing an incompetent and drunken woman from assuming the name and the duties of a midwife."3

In 1873 the Council referred the matter of branch examinations and registration of midwives to a committee, who re${ }^{1}$ Council Minutes, p. 243. 2 Obst. Trans., vol. xiv, for 1872, p. 21.
3 Obst. Trans., vol, xvii, for 1875, p. 33. 
ported as follows: 'The Obstetrical Society of London, having had repeatedly and urgently brought before its notice the sacrifice of human life and health occasioned by the practice of ignorant midwives, has already instituted an Examining Board for testing the knowledge of women desiring to follow the calling of a midwife, and has granted certificates to those who have satisfied its examiners.' It then proposed methods for branch examinations, and for the registration of midwives. ${ }^{4}$

On June 6th, 1877, the President (Dr. West) informed the Society that a deputation had waited upon the Lord President respecting the examination and registration of midwives. At the annual general meeting, January 2nd, 1878, the President (Dr. West) again referred to the subject as follows: ' His Grace the Lord President of the Council expressed himself as favourable to the principles which the scheme embodies. It was afterwards laid before the General Medical Council, who approved its object. In order to correct various legal and technical imperfections, it was submitted to $\mathrm{Mr}$. Roscoe, the legal adviser of the College of Physicians.'

The President then proceeded to deprecate the postponement of a settlement of this question till that of the admission of women to the profession was settled; and he pointed out that if women were admitted to, and even if men were excluded from, the medical profession, the poor, especially in the country districts, would be just as ill provided as at present.

He urged the duty of the Society, not as doctors but as citizens, 'to secure some guarantee that the poor shall not continue to be exposed to an ignorance and unskilfulness against which the Government of every other civilised country has protected them.' 6

In 1879 the President (Dr. Playfair) informed the Society at the annual meeting that ' the principles of the scheme [for the examination and registration of midwives] not only met with the approval of the General Medical Council, but were embodied by his Grace the Duke of Richmond in the Medical Acts Amendment Bill, which, but for the troubles in the East, would, there is every reason to believe, have passed both Houses of the Legislature."

The certificate is then quoted, and reference made to a modification when in 1889 the Chairman of the Board for the Examination of Midwives (Dr. Watt Black) reported that the Society, with the advice of Mr. Roscoe, had added a declaration or sponsio, which each midwife would have to sign, in which she agrees to submit to the jurisdiction of the Council in all matters relating to her conduct as midwife, and to give up her diploma if the Council shall consider her conduct such as to render her unworthy to hold it. This she signs in a book and also on her certificate.

Dr. Champneys declares that the Council were expressly advised by their solicitor that no technical meaning attached to the word "diploma," and that it had precisely the same meaning as "certificate." He further quotes the correspondence between the General Medical Council and the Obstetrical Society in January, 1893, when the Registrar of the Council pointed out that a certificate should be expressed in such a form as not to lead to the impression that it is a legal qualification to practise midwifery. The Society insisted that its diploma was merely an expression of opinion. This stage of the dispute ended in the well-known resolutions passed by the General Medical Council last December at the instigation of the Lancashire and Cheshire Branch of the British Medical Association. The Council objected to " documents issued by various societies or persons as diplomas of education and examination in midwifery, as they are 'colourable imitations' of diplomas conferring a legal right of admission to the Medical Register, and therefore were deceptive to the public and in contravention to the Medical Acts. The Council gave notice that the issue of such 'colourable imitations' by registered practitioners would be regarded as conduct infamous in a professional respect." The second resolution formally condemned the Obstetrical Society's diploma.

The section of the Medical Act thas "contravened in

$$
4 \text { Council Minutes, p. } 281 .
$$

5 Obst. Trans., vol. xix, for 1877, p. 136

6 Obst. Trans., vol. xx, for 1878, p. 13.

'Obst. Trane, vol. exxi for 1889, p. 7 . spirit" was then read, Dr. Champneys quoting from the JoURNAL ${ }^{8}$ on the discussion in the General Medical Council between $\mathrm{Mr}$. Wheelhouse and Dr. MacAlister, who spoke strongly of the agitation against the education of midwives. He further quoted, "as evidence that the activity of the General Medical Council had not always been well advised or in accordance with the law of the land," the report $^{9}$ of the remarkable action brought by the College of Physicians against the General Medical Council, where the verdict was for the plaintiff, Lord Justice Smith deciding that the College was a body legally qualified to grant diplomas in medicine and also (here was the contested point) in surgery.

Before proceeding to deal with the above evidence, Dr. Champneys displayed the Society's statistics. In January, $1895,2,166$ midwives were on the Society's register, and 4 had been struck off. The regulations and other matters of detail in respect of the examinations were also reviewed.

Dr. Champneys insists that the following propositions appear to be established : (1) Any person is at liberty by the law of the land to render aid to any other in time of sickness, if desired. (2) Any person is at liberty by the law of the land to receive such aid from any other. (3) Unskilled aid leads to lamentable consequences to poor mothers and children. (4) "Midwives are a necessity." Hence these necessary persons should be educated and examined. The question is not whether midwives shall exist, but whether they shall be as bad or as good as possible. The Society has considered it a duty to interest itself in the question as com. petent to act, in the absence of any State regulation, for which it has always begged. The interests of the poor are the only interests worthy of consideration. Doctors were made for the sick, and not the sick for doctors. He proceeds : "If a poor woman requires a doctor for her confinement, she can have one; if she prefers a midwife, she can have one -trained, certificated, and comparatively safe; or she can have one untrained, uncertificated, ignorant, septic, and fatal! Are there really any of her countrymen who would run the risk of leaving her only the latter alternative? As to her freedom of choice, no legislative body in the world would hand her over, tied hand and foot, to the mercy of any profession. She is free, and she can have, and will always be free to have, whom she chooses. In order to thus limit her choice it would be necessary to make it penal for her to employ any but a doctor, or to make it penal for anyone but a doctor to attend her. Does anyone imagine this for an instant to be possible? I challenge agitators to put this fairly forward in a Bill, and to speak with their enemies in the gate. I am sure that many who have joined in this attack have done it in ignorance. This is the age of cancuses and wire pullers. Men are too busy to read for themselves and think for themselves; they too easily answer leading questions in the affirmative, and sign petitions without understanding them."

Dr. Champneys observes that the profession claims to be " noble," and its nobility is due to that unselfishness which is one of its best traditions. Vaccination and the wholesale benefits of preventive medicine meant in the first instance loss of income to the whole profession, hence, the urges, the plea that trained midwives entail loss to doctors is ignoble and unprofessional. Registration of midwives is, he maintains, the best protection to the poor, as the malpraxis of registered midwives can be checked, and the Obstetrical Society's certificate ensures the desirable check. The doctor, again, has control over a midwife who has signed her name to the agreements on the certificate. The length of training, it is urged, is insufficient, but this objection shows that the objectors desire that midwives be trained, and that the same objectors should cease their opposition and assist the Society in getfing State regulation. Even the dread of competition is not universal, as the Select Committee (quoted above) reported that midwives, it was found, did not injure doctors. The Society continues the examinations purely from public spirit, and never ceases to be relieved of its responsibilities by the transference of its work to a State-regulated machine.

The President of the Obstetrical Society expresses indignation at the offensive expression " infamous in a professional

8 Vol. i, 1894, p. 1138.
9 Vol. i, 1893, p. 550. 
respect" made use of in the resolution of the General Medical Council. He concludes: "But I believe that neither Sir John Williams, Dr. Watt Black, nor I, who have acted first as Chairman of the Midwifery Board, and afterwards have been called to the presidential chair, and are therefore. perhaps, the most "infamous" among "infamous" men, feel the least ashamed of our work, conscious as we are of our own integrity, and of the great injustice which has been done to us all. As regards the form of our certificate, if the General Medical Council had told us that they thought it open to objections, we should have at once done what we are now doing-asked for its criticism with a view to their removal.

To have helped us to remove any cause of offence would have earned our gratitude.

I cannot but think that when it has mastered the subject, and had time to think, the General Medical Council will regret what it has done, not only towards men as honourable as any of its members-whose life and work are well known to it-but to a meritorious and public-spirited Society.

Meanwhile the agitators may rest assured that it has not seen the last of our examination, nor of us.

It is a significant fact that the number of candidates for our last examination has hardly ever been exceeded, not less than 114 women having presented themselves, and that in spite of our having held our certificate in abeyance.

If there is one thing certain in the world, it is the ultimate triumph of right. It may be opposed-it may be misunderstood - it may be reviled - it may have to suffer; butMagna est veritas, et prævalebit."

\section{THE ITREATMENT OF OZFNA : A PRELIMINARY NOTE.}

Ey G. HUNTER MACKENZIE, M.D.,

.Surgeon for Diseases of the Throat and Nose to the Eye, Ear, and Throat Is firmary, Edinburgh.

ON May 28th, 1890, a young lady was sent to me by Mr. G. W. Watson, L.D.S., of Edinburgh, on account of a fotid discharge from the nose. This had lately been so intense as to induce complaints from the governesses and pupils of the school which she attended, and ultimately the girl was requested to discontinue attendance. She had been taken to Mr. Watson under the impression that her teeth might be at the bottom of her trouble; but as these were found quite sound, and Mr. Watson readily recognised that ozæna was present, she was sent to me.

The patient was one of the worst examples of ozæna that I have seen. Large putrid crusts blocked both nares, and, when removed, reformed by the following day. The nose was broadened, and the alæ were thickened and reddened. The patient was put under treatment during the summer and part of the autumn of the same year, and I saw her occasionally during 1891. Treatment was entirely discontinued after 1890.

On October 27th, 1894, about four years after the discontinuance of all treatment, I received a note regarding the case from Mr. Watson, of which the following is an extract: "I -saw your old patient Miss C. recently, and thought it would interest you to know that she is quite cured of the ozæna. She says she is quite well again, and has no discharge; nor was there any odour perceptible when I examined her. She looks a different person now that she is all right."

This case, from its nature, result, and the period that has elapsed since the discontinuance of all treatment (four to five years), affords an opportunity for making a few observations preliminary to a more exhaustive communication on the subject of this distressing disease. Believing that ozæna is a disease of the mucous membrane, and that the atrophy or shrinkage which is characteristic of it is simply due to pressure of the hardened pus (crusts) upon that membrane, a condition which is somewhat analogous to that met with in the skin in certain forms of eczema, I have endeavoured by curettement to supplant the diseased membrane by new tissue, and the success I have met with in several instances, of which the above is an example, has warranted me in publishing this preliminary note. After curetting I have found oily applications, such as a mixture of ichthyol and olive oil, soothing and beneficial. I may add that the patients upon whom this method of treatment has succeeded have been young, that is, from 10 to 25 or 30 years of age.

\section{CASE OF INTRALARYNGEAL TUMOUR REMOVED BY THYROTOMY.}

By JAMES MACKENZIE BOOTH, M.D., Surgeon Aberdeen Royal Infirmary, Lecturer on Diseases of the Ear and Larynx in the University of Aberdeen.

I HAVE thought the following case worthy of being communicated to the members of the Branch, not only on account of the infrequency of the affection in this part of Scotland, but also on account of its special features, and the operative treatment necessary for its relief.

The patient, Mrs. W., a married woman, aged 38 years, who, with the exception of a quinsy fifteen years previously, had always enjoyed robust health, first noticed a disagreeable sensation in her throat, causing her to make efforts to clear it, in July, 1892, at the time of her fifth confinement. A week later she began to suffer from hoarseness, which in three weeks resulted in complete loss of voice; for this an astringent pigment for the throat and a cough mixture were prescribed. During the latter part of 1892 and the beginning of 1893 the aphonia remained much the same, varying to a slight extent with the state of the weather, somewhat less marked when warm and dry, and worse during cold and wet.

In July, 1893, her medical attendant, Dr. Cheyne, advised her to apply to the ear and throat department of the Aberdeen General Dispensary. On laryngoscopic examination there, her symptoms were found to be due to the presence of a small tumour like a pea in the anterior commissure of the larynx, of the same colour as the laryngeal mucous membrane, which was redder than normal, and attached by a broad pedicle to the anterior fourth of the free border of the left vocal cord. Fig. 1 shows the condition observed in July,

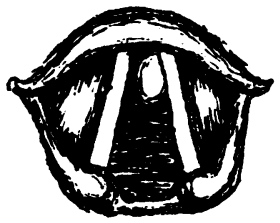

Fig. 1.-July, 1893.

1893. Attempts to examine it with the probe and establish toleration of the laryngeal surface were repeatedly made without success, even with the aid of cocaine as pigment and spray. A pigment of zinc chloride of 30 grains to the ounce of glycerine was applied twice weekly to the larynx, and the patient enjoined to use steam inhalations of pine oil twice or thrice daily. Under this treatment the congestion diminished, and the subjective symptoms were benefited, the discomfort being less and the voice, though still hoarse, returning to some extent, but no apparent diminution was observed in the growth.

Towards the commencement of the cold weather, however, her symptoms got worse; she began to suffer from attacks of dyspnœa, and she was admitted to the Royal Infirmary on

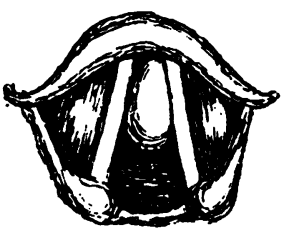

Fig. 2,-October, 1893

1 Read at the December (1894) meeting of the Abcrleen, Binff, and 